\section{THE USE AND ABUSE OF THE TERM "FEVER."}

\section{BY SAMUEL WILKS, M.D.}

IT is high time that the public should be better informed as to the matter of "fevers"; and if it could receive a little instruction from the hands of the profession, I believe the benefit conferred on the community would be immense. We medical men know that so loose an expression as "fever" is worse than worthless-that there is no more fever per se in typhus, typhoid, or scarlatina, than in a hundred other diseases; and we know also that under that vaguest of all terms, and one engendered in ignorance, "common continued fever," there have been included several totally different maladies, contagious and non-contagious. Owing, however, to the fact of many specific diseases being attended by feverishness, and many of them being contagious, the words "fever" and "contagion" convey identical ideas to the minds of an uninstructed public. The practical evil arising therefrom is very considerable, for a highly contagious affection may be disregarded, whilst a slight malady attended by pyrexia may be developed into a fatal one by an erroneous method of treatment.

I am ignorant of the objects for which the London Fever Hospital was established, but I assume it was for the purpose of isolating contagious diseases. Now the only affections which are constantly with us of this nature are scarlatina, measles, small-pox, and typhus. Small-pox has already found a home, and measles is so rarely seen in the epidemic malignant form that there is never felt any need for its isolation, so that there remain only scarlatina and typhus which require to be treated in a special institution. Owing, however, to the popular view of "fevers," any disease having such an appellation is supposed to find a proper habitat therein; and, consequently, it might happen that a non-contagious disease, "typhoid" by name, might be filling the wards to the exclusion of a wide-spreading infectious malady. It would be sent to the hospital on account of its name. Absurdity could scarcely further go. Again, if a poor servant be seized with feverish symptoms, and it be not at first apparent what is the nature of her complaint, she is sent off to the Fever Hospital, and thus the physician is obliged to treat arachnitis, pneumonia, Bright's disease, or tuberculosis. This absurdity is a fitting corollary to the other.

The reform required is, I think, very simple; for since the only diseases we wish to isolate for the benefit of the community are small-pox, scarlatina, and typhus (relapsing fever being only a wanderer amongst us), and small-pox having found a refuge of its own, the fever hospitals should be used for the two latter only. And, again, since there would be no wish to send away the mildest cases of scarlatina, and as in severer ones the rash appears on the day following the feverish symptoms, a rule might be made to admit no case without the presence of an eruption. If the same were done with regard to typhus, the public and the profession would have an easy rule to guide them, and the objects of fever hospitals be more completely fulfilled. The same idea actuating the authorities of the general hospitals would dictate to them what cases to exclude, and oblige them no longer to refuse admission to the harmless typhoid on account of its name. No term in the whole range of medicine (not excepting inflammation) has, I believe, wrought so much mischief on theoretic and practical medicine as the word "fever." If anyone would propose a good substantive expression for typhoid and relapsing fevers, we might expunge the word altogether from our nomenclature, using the term pyrexia or feverishness for the febrile state; and could the originator of such names command their extension through the ranks of the profession, he would be conferring a boon on humanity.

Grosvenor-street, December, 1870.

Mr. P. H. MacGilurvrat, surgeon to the Bendigo Hospital, reports, in the Australian Medical Journal for O trber, 1870, the successful removal of the whole tongue for epithelioma.

\section{FEMORAL HERNIA RADICALLY CURED BY OPERATION.}

BY SAMUEL WOOD, F.R.C.S.

MarX H-, aged thirty-seven, of spare but healthy habit, was admitted an in-patient of the Salop Infirmary on the evening of Sept. 7th, 1869, with a strangulated femoral hernia. She stated that she had had a hernia for eighteen months, and that on the morning of the 6th, as she was lifting a small beer-barrel, the bowel came down so that she could not return it. As the symptoms were not urgent, she was ordered ten minims of dilute hydrocyanic acid in an ounce of water. There had been slight vomiting during the night previous, and on the morning of her admission taxis was tried on two or three occasions, but without success.

Sept. 8th.-Has passed a restless night, with occasional vomiting; hernia unreduced. Chloroform having been given, the sac was cut down upon, but not opened; the strictured portion at the neck was divided, and with a little gentle pressure, the contents, consisting of intestine and omentum, returned. It then occurred to me that, if I could detach the sac from its surroundings and invaginate it, and retain it in this inverted position, the raw surfaces would form adhesions, the opening be thus plugged up, and a radical cure be effected. Acting on this idea, I carefully detached the sac, and easily succeeded in pushing it through the openings and so invaginating it. In doing so, I could with my finger detect, through the sides of the sac, the opening of the crural ring and the edge of Poupart's ligament, and feel the end of my finger, covered by the inverted sac, well within the cavity of the abdomen. 'The sac being secured in this position, the external wound was closed with wire sutures and strips of adhesive plaster, over which compresses of linen were put, and the whole secured by a roller applied in the usual manner. Forty drops of Battley's solution were given. Has vomited once or twice after the operation, but all the urgent symptoms were relieved. In the evening the bowels were moved.

9th.-Doing well; no sickness. Beef-tea, milk, tea.

10th.-The dressings were removed, and the edges of the wound found to have united beartifully.

11th.-There is a little redness on the edges of the wound, and they appear as if they would separate; a little discharge from one part.

12th.-The edges have separated nearly the whole length, and I can see a funnel-shaped depression, with granulating sides, being the inverted sac. She was allowed some wine and a more liberal diet.

From this time the case progressed uninterruptedly; the wound filled up and healed, and a pad was kept on the part to retain it in position until the parts became consolidated. She was discharged cured, and had a truss applied. I saw her some months after, and the part appeared consolidating. She was wearing the truss, and there was no hernial protrusion. I again visited this patient twelve months after the operation; the parts had becone quite consolidated, and there was no hernial protrusion.

I am not aware that this plan of permanently closing the opening, and thus radically curing femoral hexnia, has ever been done or suggested beforo. It appears to me so easy and natural a proceeding, and one attended with so little danger, that I trust the publication of this case may induce others to try this plan of operating. It may, however, happen that I am here recording what has long ago been done by others, though I have never found any notice of such an operation.

Shrewsbury, November 29th, 1870.

\section{TWO CASES OF INJURIES OF THE LIVER : WITH REMARKS.}

\section{BY GOPAUL CHUNDER ROY, F.R.C.S.}

A young Mahomedan, aged about thirty years, of intem. perate habits, came under my treatment in the Nagpore City Hospital in the year 1867, with a large abscess of the liver. With the history of acute hepatitis there was a uni- 